\title{
Raman LIDAR Detection of Cloud Base
}

\author{
Belay Demoz ${ }^{1}$, David Starr, David Whiteman, Keith Evans ${ }^{1}$, Dennis Hlavka ${ }^{2}$, Ravindra \\ Peravali $^{1}$
}

NASA Goddard Space Flight Center, Greenbelt, Maryland

\begin{abstract}
Advantages introduced by Raman lidar systems for cloud base determination during precipitating periods are explored using two case studies of light rain and virga conditions. A combination of the Raman lidar derived profiles of water vapor mixing ratio and aerosol scattering ratio, together with the Raman scattered signals from liquid drops, can minimize or even eliminate some of the problems associated with cloud boundary detection using elastic backscatter lidars.
\end{abstract}

\section{Introduction}

Accurate characterization of cloud boundaries is fundamental to understanding the radiative effect of clouds on climate. Cloudradiation interactions impact the radiation budget of the Earth, both at the surface and in the atmosphere, and are the largest source of radiation budget uncertainty [IPCC, 1995]. These interactions depend on many variables, including cloud depth, cloud top height, cloud liquid water content, water vapor profile, and solar zenith angle. The calculation of cloud optical depth, for example, requires accurate determination of cloud base and cloud top heights. Recent studies suggest that variations in cloud boundaries are even more important than variations in cloud microstructure for the calculation of cloud optical depth [Kogan and Kogan, 1998]. Han and Ellingson [1997] also indicate that cloud geometry is the primary factor that controls effective cloud fraction and is a major uncertainty in calculation of downwelling longwave flux at the surface.

Measurements of cloud horizontal extent predominantly make use of satellites [Rossow and Gardner, 1993], while characterization of cloud vertical distributions primarily rely on radar and lidar observations [Clothiaux et al. 1998, Uttal et al. 1995]. However, a number of difficulties exist in the radar-lidar observation of cloud base height. The detected cloud base height is strongly influenced by the sensing wavelength as well as the method of detection. Occurrence of rain, virga, and radar-confusing bugs in the boundary layer also complicate cloud base detection.

This work discusses advantages introduced by Raman lidar in the determination of cloud base height using the NASA Goddard Space Flight Center's Scanning Raman Lidar (SRL). The SRL provides simultaneous profile measurements of aerosol scattering ratio (ASR), water vapor mixing ratio ( $\mathrm{W}$ in $\mathrm{g} \mathrm{kg}^{-1}$ ), and relative humidity $(\mathrm{RH}$ in percent derived using co-located temperature profiles from sondes or other sensors). The Raman lidar measurements will be discussed in relation to the Micro Pulse Lidar (MPL), Belfort Laser Ceilometer (BLC) and MillimeterWavelength Cloud Radar (MMCR). Details of the SRL have been reported by Whiteman and Melfi (1999). 


\section{Cloud Base Detection}

Cloud-base detectors, available commercially and widely used by the U.S. National Weather Service, like the rotating beam ceilometer and the laser ceilometer, assume cloud base height to be the location of the peak in the lidar backscatter signal [Eberhard, 1986]. This cloud base height definition assumes that the signal is small below cloud, rises to a maximum at the start of the cloud, and decreases thereafter due to attenuation. Thus, most techniques used for cloud base height detection search for zero crossings in the derivative of the returned signal [Pal et al. 1992, Campbell et al. 1998, Gaumet et al. 1998]. Other methods look for a "threshold" value of signal shift from the background [Platt et al. 1994] or construct lidar clear-sky power return profiles from archived data to test for the presence of clouds [Clothiaux et al. 1998]. Noise estimates and/or smoothing are used in some of these techniques to reject false peaks resulting from cloud inhomogeneity, aerosols and signal noise.

The above definitions of cloud base height are not as straightforward as they might appear. They are influenced by the instrument wavelength, and the fact that appropriate definition of cloud base height may depend upon the particular research problem to be addressed. For surface radiation budget studies, for example, cloud base height may refer to the radiatively important part of the cloud and neglect any virga-associated excursions, while for visibility applications, such as pilot/flight safety, alternative criteria may be required.

Although cloud base height is routinely assumed to be the location of the peak in the lidar backscatter signal, it is well known that this is an overestimation. The difference in altitude between the point where the signal starts to increase and its peak can be as large as $800 \mathrm{~m}$ [Pal et al. 1992]. Pilot-reported cloud base height, for example, is usually lower by as much as $240 \mathrm{~m}$ than that detected by the rotating beam ceilometer [Pal et al. 1992]. The difference between the two levels, i.e., where the signal starts to increase and where it peaks, is a function of the physical interaction between the cloud and the instrument signal. Instruments operating at shorter wavelengths (near visible) respond to smaller size droplets, like those found near the base of non-precipitating clouds, that might not be detected at longer wavelengths such as used by radar.

Additional complications arise in the detection of cloud base height for high altitude clouds. High cirrus clouds often exhibit complex inhomogenous structures and may have rapid changes in cloud base height and the lidar signals often have low signal-tonoise-ratio as compared to boundary layer clouds. Thus, cloud base height algorithms must distinguish between signal shifts due to random noise and cloud base height. These differences can be challenging in the case of thin cirrus clouds [Sassen and Cho, 1992 ].

Problems in cloud base height detection also arise when the lidar signal does not undergo a sudden increase (as in fog or the initial phase of cloud formation), when multiple peaks occur in close proximity (multiple cloud layers not well separated) and at times of precipitation or haze between cloud and the instrument. Rain and virga introduce large errors in the detection of cloud base height, although, in principle, one can differentiate between regions of precipitation and cloud from the rate of the slope of the backscattered signal [Pal et al. 1992]. 


\section{Raman Lidar Contribution}

In addition to the elastic backscatter signal at the transmitted wavelength, Raman lidar systems detect signals from water vapor, nitrogen and oxygen molecules and from cloud liquid water, due to Raman scattering at wavelengths shifted from the laser wavelength [Melfi, 1972, Melfi et al. 1997]. Raman lidar measurement of water vapor mixing ratio is made using the ratio of signals at the shifted water vapor and nitrogen frequencies. The extra information provided by Raman lidars, and particularly the water vapor and cloud liquid water signals, can be used to resolve some of the problems in cloud base height detection. In particular, relative humidity calculated from the water vapor mixing ratio, the Raman signal from liquid cloud drops, and the attenuation of the signals, together with the elastic backscatter at the transmitted wavelength, can be used collectively to infer cloud base height. In principle, sensitivity to the molecular processes makes the Raman signal immune to virga and/or light precipitation and removes the dependence of cloud boundary definition on instrument wavelength. Thus, information on the water vapor and nitrogen profile can be retrieved even during virga and/or precipitation which is either not possible or not reliable using other single channel elastic lidars. The Raman system is immune to the so-called plankton problem, where bugs and other large suspended particles complicate cloud/non-cloud boundary, and seriously limit radar based cloud base height detection accuracy for low level clouds in some seasons.

\subsection{September 1997: Virga}

Figure 1 shows analyses of the SRL, Belfort Laser Ceilometer, and Micro Pulse Lidar data for 28 September 1997 observed at the Department Of Energy Atmospheric Radiation Measurement site near Lamont, Oklahoma. Microwave radiometer (MWR) measured vertically integrated cloud liquid water path (in $\mathrm{mm}$ ) are also included. Note that the Raman lidar data used here are nighttime only. Detailed analysis of wind profiler data, synoptic maps, Raman lidar and other data sets indicated that the clouds on this day were formed as a result of convergent lifting of low level moist air. Cloud level winds were less than $10 \mathrm{~m} \mathrm{sec}^{-1}$.

As illustrated in Figure 1, cloud base height derived from all three instruments (i.e., SRL, MPL and BLC) compared well, except at about 0600,1300 and 1700 . This is not surprising because these cloud base heights for all three were derived from the elastic backscatter signal (ASR), albeit using different algorithms and wavelengths $\quad\left(\lambda_{\text {SRL_vapor }}=408 \mathrm{~nm}, \quad \lambda_{\text {SRL_nitrogen }}=387 \mathrm{~nm}\right.$, $\lambda_{\mathrm{SRL} \_ \text {aser }}=355 \mathrm{~nm} ; \lambda_{\mathrm{BLC}}=910 \mathrm{~nm} ; \lambda_{\mathrm{MPL}}=523 \mathrm{~nm}$ ). The Raman lidar cloud base heights were derived using a simple "threshold" method where cloud base height is defined as the level at which the signal is twice the background value and continues to increase (or does not decrease) for at least some distance above. The micro pulse lidar cloud base heights were derived using the ScottSpinhirne threshold algorithm (Clothiaux et al. 1998). The algorithm employed by the Belfort Laser Ceilometer, although proprietary, is similar to that of $\mathrm{Pal}$ et al. (1992).

Around 0600,1300 and 1700 , the lidars generate several different cloud base heights, within a very short time interval, indicating problems as they attempt to identify the base height of the cloud layers. Coincident observations by MMCR indicated virga conditions at these times that can confuse elastic backscatter-based 
cloud base height detection. Profiles of SRL (Micro pulse lidar) measured aerosol scattering ratio (estimated backscatter), sonde and Raman lidar measured water vapor mixing ratio $\left(\mathrm{g} \mathrm{kg}^{-1}\right)$ and relative humidity $(\%)$ profiles, and the dew point depression (T$\mathrm{T}_{\mathrm{d}}$, in ${ }^{\circ} \mathrm{C}$ ) at 0531,0600 and 0830 are plotted in Fig. 2.

The 0531 sounding $\left(T-T_{d}\right.$, dotted line, in Fig. $\left.2 A\right)$ indicated a cloud deck from 2.6 to $3.1 \mathrm{~km}$ and a second nearly saturated shallow layer from 4.2 to $4.3 \mathrm{~km}$. The lower cloud layer is resolved by Raman lidar-measured aerosol scattering ratio profile (heavy dash-dot line). The peak return occurs about $100 \mathrm{~m}$ above cloud base (twice background). Cloud top height is slightly overestimated by the SRL in comparison to the sonde data. The agreement is fairly good. This is also true for the 0830 (Fig. 2D) profiles where only the lower cloud layer remains. The 0600 profiles (Fig. 2B), however, are problematic. Although the micro pulse and Raman lidar profiles do not correspond exactly (mainly due to a difference in signal averaging time and instrument separation), they indicate three or more cloud layers. However, a close scrutiny of the data will show that only two layers exist. It is interesting that a minimum ("dip") is found about $150 \mathrm{~m}$ below the $0^{\circ} \mathrm{C}$ level (above a peak at $3.7 \mathrm{~km}$ ) in both the micro pulse and Raman lidar profiles (Fig. 2B). This feature is typical of the socalled "lidar dark band" [Sassen and Chen 1995], which is associated with the structural collapse and accumulation of melted snowflakes and their transition to spherical drops. Thus, the peak at $3 \mathrm{~km}$ should not be classified as a cloud layer. First, the fact that the lidar signals did not get heavily attenuated and gave information above the clouds (above $4.2 \mathrm{~km}$ ) is a good indication that the clouds were not optically thick and therefore not deep (optical thickness at 0600 between 2.5 to $4.3 \mathrm{~km}$ was 1.4 , less than the 2.6 calculated at 0800 for the layer between 2.5 and $3.5 \mathrm{~km}$ ). Second, the sounding at 0531 (and 0800) indicated sub-saturated conditions from $3 \mathrm{~km}$ to near $4 \mathrm{~km}$. Finally, the water vapor mixing ratio and correspondingly relative humidity values between 3 and $4 \mathrm{~km}$ far exceed saturation values. This is unrealistic. Note the apparent moistening in the layer immediately below the lidar dark band that is indicated by the SRL profile at 0600 (Fig. 2C). This is attributed to additional signal in the water vapor channel due to Raman scattering from liquid drops (see Whiteman and Melfi, 1999) in addition to evaporation of the falling drops. Thus, around 0600 , only two cloud layers existed; a layer between 2.6 and $3 \mathrm{~km}$ and another precipitating cloud between 4 to $4.2 \mathrm{~km}$, most likely a glaciated altostratus cloud with virga between the cloud layers. This is supported by MMCR observations of virga around 0600 originating from the upper cloud. In such conditions, single channel lidars will have great difficulty in locating the cloud base height, even when using sophisticated algorithms. We suspect the same complications caused by virga in detecting cloud base height by the lidars at 0600 are also the causes for the multilayer cloud indications at 1300 and 1700 .

Excess vapor (a bump in the SRL profile compared to the sonde values) was observed near cloud base $(2.8$ to $3 \mathrm{~km})$ in the 0830 profile while virga was not reported by the MMCR. Raman measurements of water vapor mixing ratio obtained in the presence of liquid cloud drops are enhanced by the Raman signal from the drops. Separation of the vapor and liquid Raman scattering into separate signals will simplify the processes of cloud/virga detection. Fortunately, the vapor and liquid water Raman bands have sufficient wavelength difference to allow separate detection 
of liquid and this capability is currently being designed for the SRL system [Whiteman and Melfi, 1999]. In the absence of virga conditions, the "excess vapor" due to Raman scattering from cloud drops is a clear indicator of the onset of cloud water drops and hence is a direct indicator of cloud base height. The relative humidity, derived from the corrected water vapor profile, will also serve as an indirect indicator of cloud base height. In addition to cloud base height, the water vapor profiles show the moistening of the layer leading to cloud formation, even in conditions of virga and precipitation.

\subsection{August 1998: Rain}

Recent improvements in the SRL housing trailer allows for allweather operation, including rain conditions. An example of data during such conditions, observed on 27 August 1998 at Andros Island, Bahamas, as part of the Convection And Moisture EXperiment (CAMEX-3) field campaign, is shown in Figure 3. Aerosol scattering ratio and water vapor mixing ratio profiles are shown at two selected times: at .0400 when precipitation reached the surface (Fig. 3A) and at 0745 (Fig. 3B). Rawinsonde measured dewpoint depression at 0745 is also plotted in Fig. 3C. At 0400 , near-surface aerosol scattering ratio values were about five times the background, when precipitation was recorded at the ground. Aerosol scattering ratio increased monotonically to 4.2 $\mathrm{km}$ followed by a "dip" to a minimum at $4.6 \mathrm{~km}$ and then a peak at $5 \mathrm{~km}$, before returning to near-background levels. This peakdip-peak structure near the freezing level is the lidar-dark band described previously. A similar shape in aerosol scattering ratio and water vapor mixing ratio profiles was also observed at 0745 . Given only backscatter information (which is the case for most elastic lidars), the threshold technique of determining cloud base height will not work and most other algorithms would have difficulties. An alternative solution could utilize available radiosonde information or depolarization ratio [Platt et al. 1994]. With Raman lidar systems, however, the water vapor mixing ratio channel may be used. Note that the water vapor channel at $0400(0745)$ provided usable data up to $5.1(5.4) \mathrm{km}$, close to the peak above the lidar dark band in the aerosol scattering ratio profile. Above $5.1(5.4) \mathrm{km}$, the lidar signals were severely attenuated (this occurs for optical depth greater than about 5). The lidar-derived relative humidity (using sonde temperature, not shown) indicated saturation was reached at an altitude of $5.2 \mathrm{~km}$, slightly lower than the peak in aerosol scattering ratio. From the 0745 sonde, the altitude of the smallest dewpoint depression was $5.2 \mathrm{~km}$, in agreement with the lidar-derived cloud base height, confirming the utility of the Raman water vapor signal for cloud base height detection in rain (0400) or virga (0745) conditions.

\section{Summary}

Problems in current methods of cloud base height determination during precipitation conditions using single channel elastic backscatter profiles are discussed. In some cases, the errors can be substantial. Principles of a possible new approach, based on application of the NASA/GSFC SRL derived aerosol scattering ratio, water vapor mixing ratio (and derived humidity profile) and cloud liquid water drops (measured as "apparent" excess in water vapor mixing ratio) are outlined. Measurement of cloud base height using this new approach is demonstrated and applied to 
light rain and non-rain cases. Results of this approach revealed that the lidar-based cloud base heights in non-rainy conditions compared well with those from micropulse lidar and Belfort laser ceilometer. Raman lidar-based retrieval of cloud base height and water vapor mixing ratios, during light rain and virga conditions, was demonstrated, which is impossible or highly problematic using elastic lidars. These results suggest that, where available, Raman lidar systems can add substantial information to cloud boundary studies in diverse weather conditions. The capability to simultaneously utilize the aerosol scattering ratio, water vapor mixing ratio, and Raman scattering from liquid water makes Raman systems a powerful tool for cloud boundary studies.

Acknowledgments. This research was supported by the Environmental Science Division of the U. S. Department of Energy as part of the ARM program and the atmospheric radiation and dynamics program under Dr. Ramesh Kakar of the U.S. National Aeronautical and Space Adminstration.

\section{Reference}

Eberhard, W. L., Cloud signals from lidar and rotating beam ceilometer compared with pilot ceiling, J. Atmos. Oceanic Technol., 3, 499-512, 1986.

Campbell, J. R., D. L. Hlavka, J. D. Spinhime, D. D. Turner, and C. J. Flynn, Operational Cloud Boundary Detection and Analysis from Micro Pulse Lidar Data, Proc. of the 8th ARM Science Team Meeting, U.S. Department of Energy, 119-122, 1998.

Clothiaux, E. E., G. G. Mace, T. P. Ackerman, T. J. Kane, J. D. Spinhirne, and V. S. Scott, An automated algorithm for detection of hydrometer returns in micropulse lidar data. J. Atmos. Oceanic Technol., 15, 1035 $1042,1998$.

Gaumet, J. L., J. C. Heinrich, M. Cluzeau, P. Pierrard, J. Prieur, Cloud base height measurements with a single pulse erbium-glass laser ceilometer. J. Atmos. Oceanic Technol., 15 37-45, 1998.

Han, D. and R. G. Ellingson, A test of the validity of cumulus cloud parameterizations for longwave radiation calculations, Proc. of the 7 th ARM Science Team Meeting, CONF-970365, U.S. Department of Energy, 27-31, 1997.

IPCC, Radiative Forcing of Climate Change, eds. J. T. Houghton, et. al., Cambridge University Press, 339 pp., 1995.

Kogan, Z. N. and Y. L. Kogan, The effect of cloud geometrical thickness variability on optical depth, Proc. of the 8 th ARM Science Team Meeting, U.S. Department of Energy, 377-380, 1998.

Melfi, S. H., Remote measurement of the atmosphere using Raman scattering, Applied Optics, 11, 1605-1610, 1972.

Melfi, S. H., K. D. Evans, J. Li, D. Whiteman, R. Ferrare, G. Schwemmer, Observation of Raman scattering by cloud droplets in the atmosphere, Applied Optics, 36, 15, 3551-3559, 1997.

$\mathrm{Pal}, \mathrm{S}$. R, W. Steinbrecht, and A. Carswell, Automated method for lidar determination of cloud-base height and vertical extent, Applied Optics, 31, 1488-1494, 1992 .

Platt, C. M., and Co-authors, The Experimental Cloud Lidar Pilot Study (ECLIPS) for cloud-radiation research. Bull. Amer. Meteor. Soc., 75, 1635-1654, 1994.

Rossow, W. B. and L .C. Gardner, Cloud detection using satellite measurements of infrared and visible radiances for ISCCP. J. Climate, 6, 2341-2369, 1993.

Sassen, K, and T. Chen, The lidar dark band: An oddity of the radar bright band analogy, Geophysical Research Letters, 22, 3505-3508, 1995.

Sassen, K., and B. S. Cho, Subvisual-thin cirrus lidar data set for satellite verification and climatological research. J. Appl. Meteor., 31, 1275$1285,1992$.

Uttal, T. and Co-authors, Cloud boundary statistics during FIRE IL, $J$. Atmos. Sci., 53, 4276-4284, 1995.

Whiteman, D., and H. Melfi, Cloud liquid water, mean droplet radius and number density measurements using a Raman lidar, J. Geophysical Research 104, 31411-31419, 1999. 
Belay Demoz, NASA/GSFC and JCET/UMBC Department of Physics, Code 913, Greenbelt, MD, 20771 (e-mail: bdemoz@climate.gsfc.nasa.gov). David Starr, NASA/GSFC Code913, Greenbelt, MD, 20771 (e-mail: starr@climate.gsfc.nasa.gov). David Whiteman, NASA/GSFC Code 924, Greenbelt, MD, 20771 (e-mail: david.whiteman@gsfc.nasa.gov).

Received, Revised, accepted

'University of Maryland Bal timore County, Baltimore, MD

${ }^{2}$ Science Systems and Applications Inc, Greenbelt MD

Figure 1. Time series of (a) Microwave Radiometer (MWR) integrated liquid water content and (b) cloud base height determined from measurements of scanning Raman lidar (SRL, plus), Belfort Laser Ceilometer (BLC, open circles), and Micro Pulse Lidar (MPL, crosses). Note that in order to make the symbols discernible the vertical axis between 2.5 to $3.5 \mathrm{~km}$ is expanded and only 1 in 10 of the points are plotted in (b). The location for the $0^{\circ} \mathrm{C}$ level and the MMCR virga observation times are also indicated.

Figure 2. Profiles of SRL-measured aerosol scattering ratio (ASR, dash-dot) and water vapor mixing ratio (W, solid with error bars), and sonde derived dewpoint depression (T-Td, dotted) and water vapor mixing ratio (W, thin solid) are plotted at (a) 0531 , (b and c) 0600 and (d) 0830 UTC. The freezing level is also indicated.

Figure 3. Typical profiles of SRL-measured aerosol scattering ratio (ASR, dash-dot) and water vapor mixing ratio (W, heavy solid) from (a) rain at 0400 UTC and (b) virga at 0745 UTC conditions for the 27 August, 1998 case. (C) Sonde derived profile of the dewpoint depression ( $T-T_{d}$ ) at 0745 is plotted for comparison. The freezing level, cloud base height and lidar dark-band positions are also indicated.

Figure 1. Time series of (a) Microwave Radiometer (MWR) integrated liquid water content and (b) cloud base height determined from measurements of scanning Raman lidar (SRL, plus), Belfort Laser Ceilometer (BLC, open circles), and Micro Pulse Lidar (MPL, crosses). Note that in order to make the symbols discernible the vertical axis between 2.5 to $3.5 \mathrm{~km}$ is expanded and only 1 in 10 of the points are plotted in (b). The location for the $0^{\circ} \mathrm{C}$ level and the MMCR virga observation times are also indicated.

Figure 2. Profiles of SRL-measured aerosol scattering ratio (ASR, dash-dot) and water vapor mixing ratio (W, solid with error bars), and sonde derived dewpoint depression (T-Td, dotted) and water vapor mixing ratio (W, thin solid) are plotted at (a) $0531,(\mathrm{~b}$ and c) 0600 and (d) 0830 UTC. The freezing level is also indicated.

Figure 3. Typical profiles of SRL-measured aerosol scattering ratio (ASR, dash-dot) and water vapor mixing ratio (W, heavy solid) from (a) rain at 0400 UTC and (b) virga at 0745 UTC conditions for the 27 August, 1998 case. (C) Sonde derived profile of the dewpoint depression ( $\mathrm{T}-\mathrm{T}_{\mathrm{d}}$ ) at 0745 is plotted for comparison. The freezing level, cloud base height and lidar dark-band positions are also indicated.

DEMOZ ET AL.: RAMAN LIDAR DETECTION OF CLOUD BASE

DEMOZ ET AL.: RAMAN LIDAR DETECTION OF CLOUD BASE

DEMOZ ET AL.: RAMAN LIDAR DETECTION OF CLOUD BASE

DEMOZ ET AL.: RAMAN LIDAR DETECTION OF CLOUD BASE

DEMOZ ET AL.: RAMAN LIDAR DETECTION OF CLOUD BASE 
Raman LIDAR Detection of Cloud Base

FIGURES 


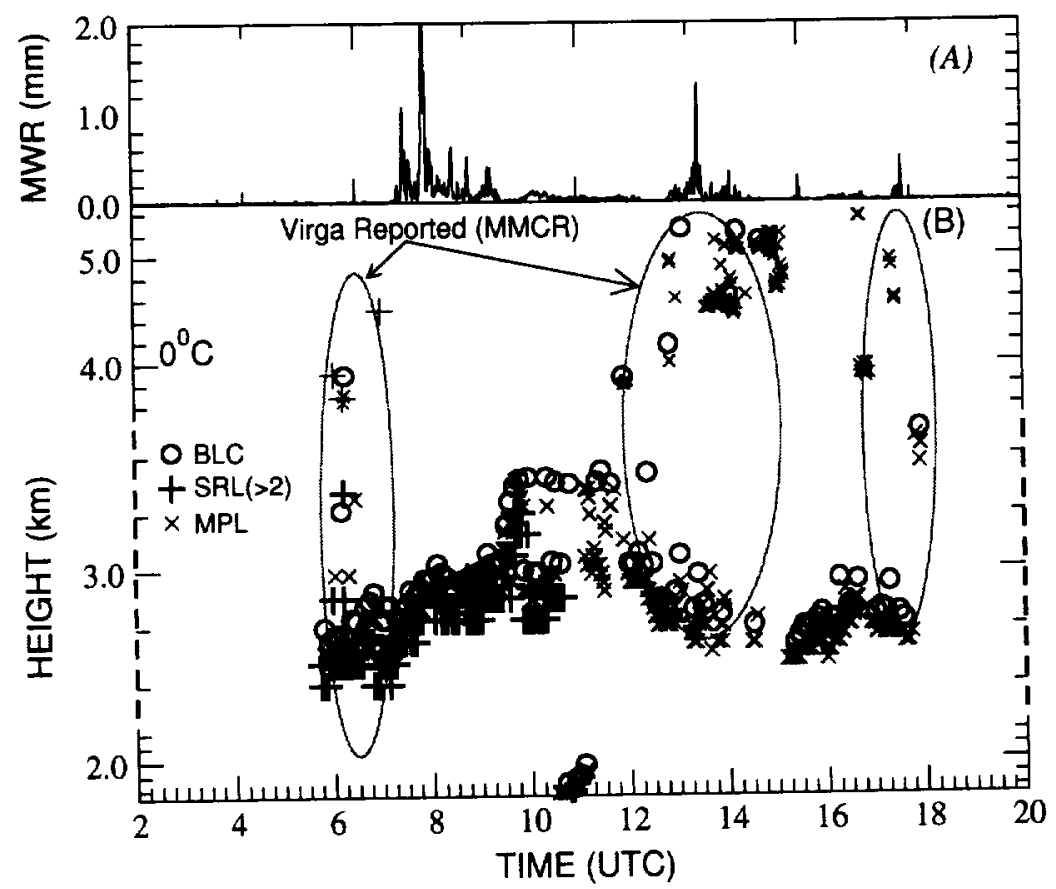

Figure 1 


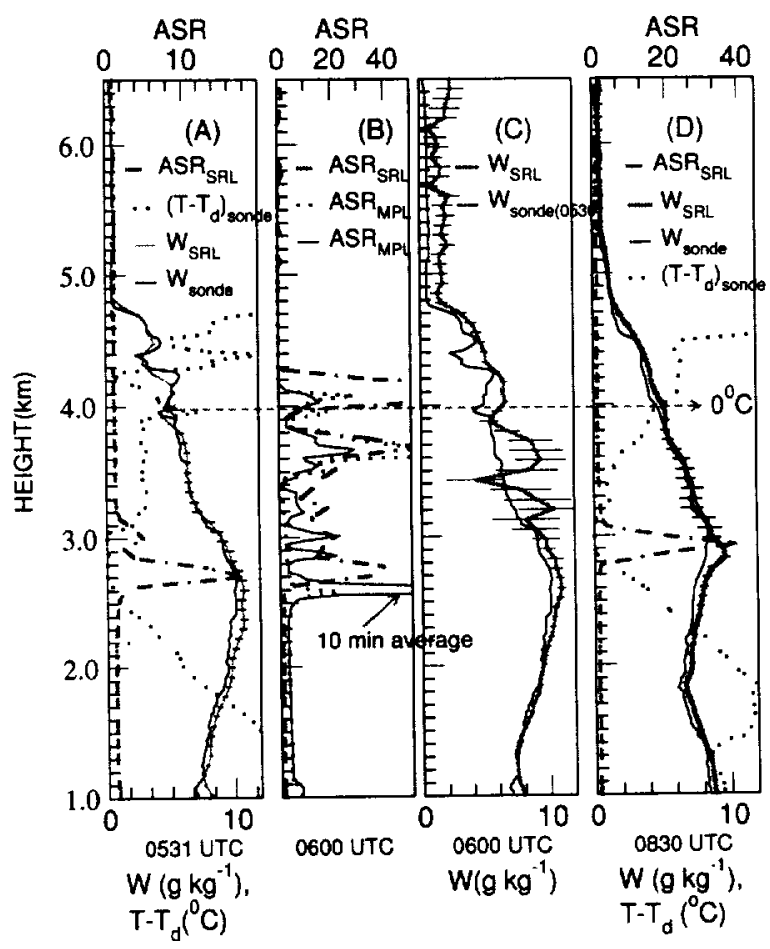

Figure 2 


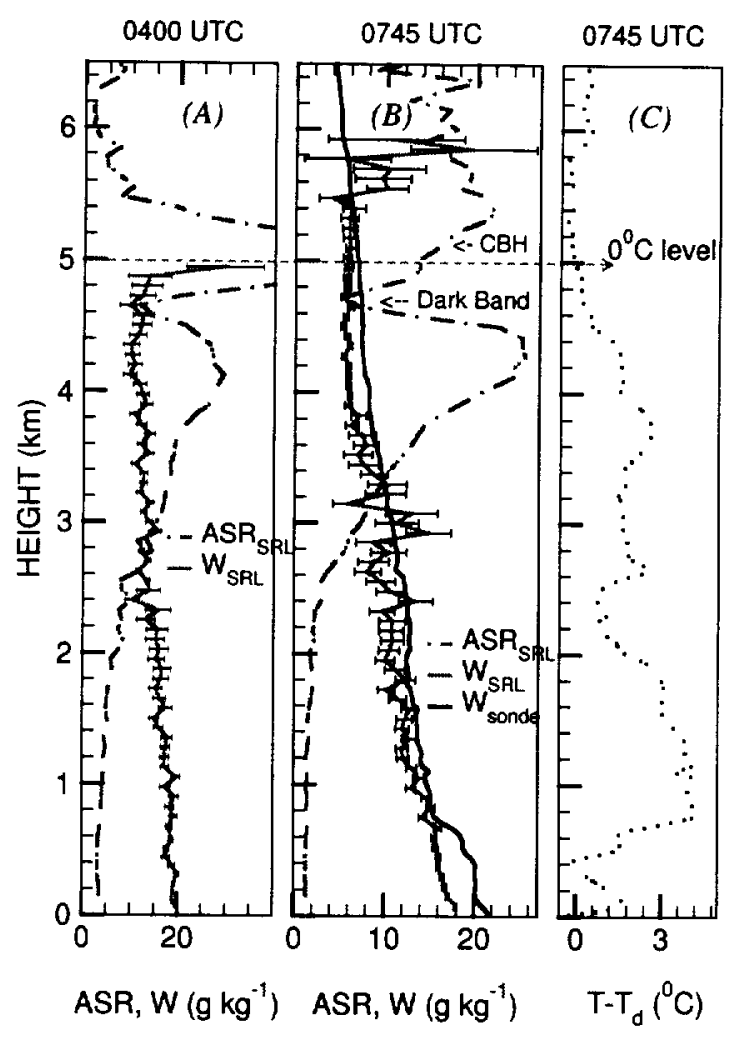

Figure 3 